\title{
Research Progress of Optical Fabrication and Surface-Microstructure Modification of SiC
}

\author{
Fang Jiang, ${ }^{1,2}$ Yan Liu, ${ }^{1}$ Yong Yang, ${ }^{1}$ Zheng-Ren Huang, ${ }^{1}$ \\ Dan Li, ${ }^{1,2}$ Gui-ling Liu, ${ }^{1}$ and Xue-Jian Liu ${ }^{1}$ \\ ${ }^{1}$ State Key Laboratory of High Performance Ceramics and Superfine Microstructure, Shanghai Institute of Ceramics, \\ Chinese Academy of Sciences, Shanghai 200050, China \\ ${ }^{2}$ Graduate University of the Chinese Academy of Sciences, Beijing 100049, China
}

Correspondence should be addressed to Yong Yang, yangyong@mail.sic.ac.cn

Received 3 October 2012; Accepted 11 December 2012

Academic Editor: Yongsheng Li

Copyright () 2012 Fang Jiang et al. This is an open access article distributed under the Creative Commons Attribution License, which permits unrestricted use, distribution, and reproduction in any medium, provided the original work is properly cited.

\begin{abstract}
$\mathrm{SiC}$ has become the best candidate material for space mirror and optical devices due to a series of favorable physical and chemical properties. Fine surface optical quality with the surface roughness (RMS) less than $1 \mathrm{~nm}$ is necessary for fine optical application. However, various defects are present in SiC ceramics, and it is very difficult to polish $\mathrm{SiC}$ ceramic matrix with the $1 \mathrm{~nm}$ RMS. Surface modification of $\mathrm{SiC}$ ceramics must be done on the $\mathrm{SiC}$ substrate. Four kinds of surface-modification routes including the hot pressed glass, the $\mathrm{C} / \mathrm{SiC}$ clapping, $\mathrm{SiC}$ clapping, and Si clapping on $\mathrm{SiC}$ surface have been reported and reviewed here. The methods of surface modification, the mechanism of preparation, and the disadvantages and advantages are focused on in this paper. In our view, PVD Si is the best choice for surface modification of SiC mirror.
\end{abstract}

\section{Introduction}

At present, mirror systems as the most important device are applied commonly in the optical system with high precision. Until now, three generations of reflector materials have been developed. The first generation is glass-ceramic; the second one is mainly made of metal, such as Beryllium metal and its alloys; the third generation of the reflector material is based on silicon carbide. SiC may be the best material available for mirror optics because of its outstanding combination of thermal and mechanical properties. It has remarkable dimensional stability even under the disturbances of temperature, humidity, and chemicals. Its specific stiffness and elastic modulus are higher than that of beryllium, which has toxicity. The density of $\mathrm{SiC}$ is slightly higher than aluminum and its fracture toughness is higher than glass. The remarkable properties of $\mathrm{SiC}$ in terms of hardness, stiffness, and thermal stability combined with a reasonable density are indeed of primary importance for all space applications. This combination of material advantages makes $\mathrm{SiC}$ an excellent material candidate for space optical instruments $[1,2]$.

Based on microstructure and processing routes, four kinds of $\mathrm{SiC}$ ceramics including hot-pressed $\mathrm{SiC}$ (HP-SiC), reaction-bonded $\mathrm{SiC}(\mathrm{RB}-\mathrm{SiC})$, sintered $\mathrm{SiC}(\mathrm{S}-\mathrm{SiC})$, and chemical vapor deposition $\mathrm{SiC}$ (CVD-SiC) were developed. The properties of different $\mathrm{SiC}$ materials and the brief description of various $\mathrm{SiC}$ component manufacturing techniques are summarized in Table $1[2,17]$. Whatever the preparation process, it is difficult to obtain high-quality optical surface due to polishing the bare $\mathrm{SiC}$ very difficultly. Moreover, microstructure defects, like pores, steps at different phases, and grain boundary damages, are unavoidable under certain surfacing condition and present further difficulty in polishing this material. The AFM topography images of surfaces polished by $1 \mathrm{um}$ abrasive grains of different $\mathrm{SiC}$ ceramics are shown in Figure 1. The steps still exist at the interfaces between two phases both in RB-SiC and S$\mathrm{SiC}$, and it cannot meet the optical requirements $(<1 \mathrm{~nm}$ RMS). The rms surface roughness values of $\mathrm{SiC}$ ceramics 
TABLE 1: Different preparation methods and properties of silicon carbide.

\begin{tabular}{lcccccc}
\hline Materials & Density $\left(\mathrm{g} / \mathrm{cm}^{3}\right)$ & Free state of $\mathrm{Si}$ & Isotropic & Cost & Preparation cycle & Surface modification \\
\hline HP-SiC & 3.20 & No & Bad & High & Short term & Requirement \\
RB-SiC & 3.04 & Yes & Good & Low & Short term & Requirement \\
S-SiC & 3.10 & No & Worse & Lower & Long term & Requirement \\
CVD-SiC & 3.21 & No & Best & High & Long term & Nonrequirement \\
\hline
\end{tabular}

are $6.464 \mathrm{~nm}$ and $3.017 \mathrm{~nm}$ [18]. The high hardness and complex crystal-phase structure of the $\mathrm{SiC}$ material indicate that the fabrication of high precision optical components is costly and slow. The key to solving this problem is to select the appropriate preparation process for surface modification of $\mathrm{SiC}$ matrix material, the dense $\mathrm{SiC}$ mirror optics plated coating, and the coating polishing. Efficiency of surface finishing for large optical components can be greatly improved as well. Moreover, microstructure defects on polished surface of $\mathrm{SiC}$ ceramic mentioned above can be covered up by the coating process. This paper presents the optical surface processes and the recent developments of $\mathrm{SiC}$ substrate by hot pressed glass, $\mathrm{C} / \mathrm{SiC}$ clapping, CVD- and PVD-coated SiC and Si coating method in detail [19-21].

\section{Optical Fabrication of Silicon Carbide}

However, $\mathrm{RB}-\mathrm{SiC}$ is typically a difficult material to machine. $\mathrm{SiC}$ is harder than most other materials except diamond, cubic boron nitride $(\mathrm{cBN})$, and boron carbide $\left(\mathrm{B}_{4} \mathrm{C}\right)$, and hence available cutting tool materials for machining $\mathrm{RB}-\mathrm{SiC}$ are very limited. Recent efforts have focused on the precision machining of $\mathrm{RB}-\mathrm{SiC}$ by grinding, lapping, polishing, and combinations of these [24, 25]. Main features and classification of optical fabrication methods of $\mathrm{SiC}$ are shown in Table 2 [26-28].

\section{Surface Modification}

Surface modification of $\mathrm{SiC}$ material is to add a thick film coating to the substrate of $\mathrm{SiC}$ for obtaining better surface quality and easier polishing. After fine polishing, the surface shows an extremely smooth surface and it can meet the optical requirement. The earliest study method is hot pressing glass, the recent developments of $\mathrm{SiC}$ surface modification is CVD- and PVD-coated $\mathrm{SiC}$ and $\mathrm{Si}$, and $\mathrm{C} / \mathrm{SiC}$ clapping is also applied to space optical devices.

3.1. Hot Pressed Glass. The hot pressed glass process was developed by the German IABG Company and the thin preshaped borosilicate glass plate is thoroughly pressed to a preground $\mathrm{C} / \mathrm{SiC}$ substrate at elevated temperature near the glass softening temperature. After cooling down, the glass plate is bonded to the substrate without the use of any adhesive. The resulted layer of approximate $1 \mathrm{~mm}$ thickness is well and economically polishable. But there are some drawbacks for usage of the glass cladding on large surfaces. For example the application of the high pressure led to the
CTE mismatching and residual internal stresses. Now, this process has rarely been used in the size of a large mirror [29].

3.2. Si/SiC Clapping. The $\mathrm{Si} / \mathrm{SiC}$ claddings are processed by an economic deposition of SiC-containing slurry onto the preground surface. Subsequent ceramization of the deposited cladding by thermal treatment leads to the conversion of the slurry cladding into a dense and homogeneous two-phase ceramic surface layer consisting of $\mathrm{SiC}$ and silicon. The Si/SiC layer exhibits a strong chemical bonding on the $\mathrm{C} / \mathrm{SiC}$ base material due to its related chemical nature. By optimizing the ratio of $\mathrm{Si}$ to $\mathrm{SiC}$ in the layer, its CTE can be tuned to match with that of the $\mathrm{C} / \mathrm{SiC}$ bulk material over a very broad temperature range. This is important for a thermally stable mirror. Although the described two-phase $\mathrm{Si} / \mathrm{SiC}$ cladding might not be suitable for superpolished surfaces below $1 \mathrm{~nm}$ RMS microroughness, the advantages of the $\mathrm{Si} / \mathrm{SiC}$ cladding technology for conventional optical components can be summarized as that surface roughness with $<2 \mathrm{~nm}$ RMS can be obtained with standard optical polishing techniques. A series of studies for this technology [29-31] have been reported by IABG and DSS company.

3.3. SiC Clapping. SiC clapping has the same mechanical properties and thermal physical properties as the $\mathrm{SiC}$ matrix, so that SiC clapping as a surface modification coating of silicon carbide mirrors attracts extensive attention of researchers. SiC coatings exhibit many outstanding properties, like good isotropic, high hardness, high thermal conductivity, and excellent optical performance characteristics. The amorphous SiC coating prepared by PVD technique with the low temperature and short cycle has also been reported.

3.3.1. CVD SiC Clapping. Chemical vapor deposition has been widely applied in thick-film preparation from the 1960s, and its principle is that the reaction materials resulted from the decomposition of Si-containing precursors are deposited on the substrate surface to form a thin film. The film is of good uniformity and repeatability. Such a method is applied to the preparation of $\mathrm{SiC}$ coating. Polished CVD-SiC (crystalline cubic $\alpha$-SiC) holds also good physical properties for making mirrors such as low density, high melting point, and low expansion coefficient.

The main precursors for $\mathrm{CVD} \mathrm{SiC} \mathrm{is} \mathrm{CH}_{3} \mathrm{SiCl}_{3}$, and the reaction equations are as follows: $\mathrm{CH}_{3} \mathrm{SiCl}_{3}(\mathrm{~g}) \rightarrow \mathrm{SiC}(\mathrm{s})+$ $3 \mathrm{HCl}(\mathrm{g})$. The dense $\mathrm{SiC}$ coating with excellent optical properties (surface roughness $<0.3 \mathrm{~nm}$ RMS) can be obtained. It can meet the application requirements of the mirror surface 


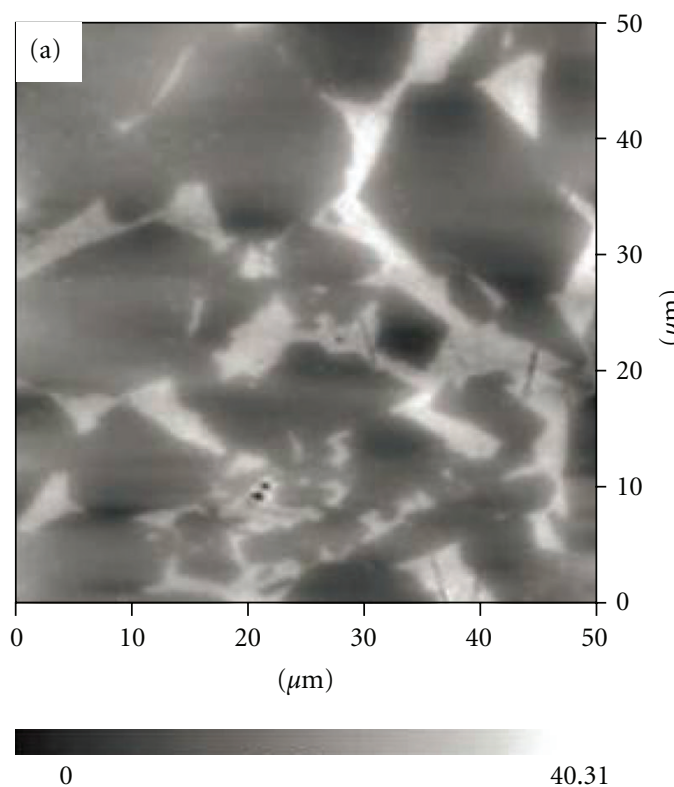

$(\mathrm{nm})$

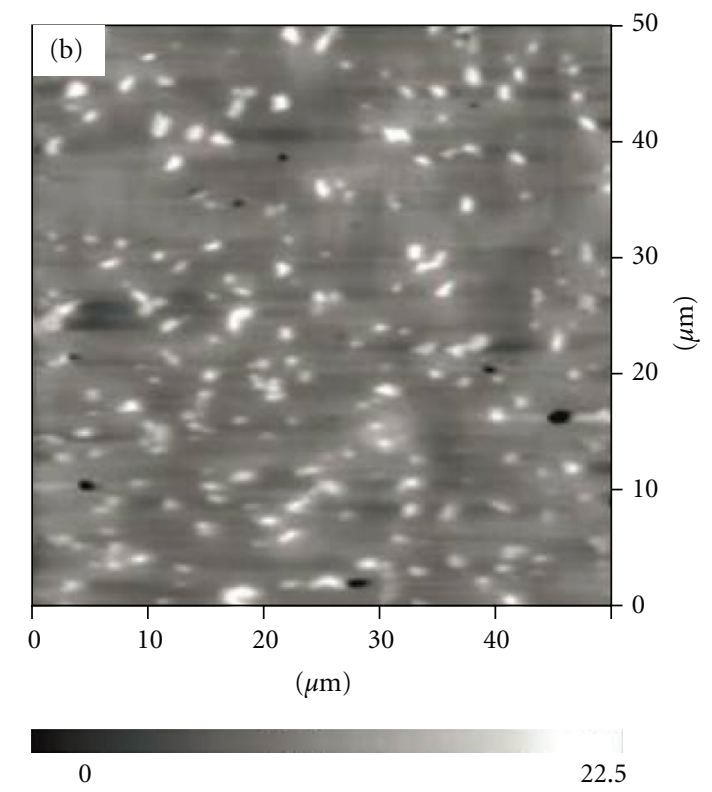

$(\mathrm{nm})$

FIGURE 1: AFM images of SiC surfaces polished by 1 um abrasive grains within $50 \mathrm{um} \times 50$ um area: (a) RB-SiC, (b) S-SiC, reprinted with permission from [18].

TABLE 2: Main features of optical fabrication methods of SiC.

\begin{tabular}{|c|c|c|c|}
\hline $\begin{array}{l}\text { Optical fabrication of } \\
\text { silicon carbide }\end{array}$ & Principle & Characteristic & Example \\
\hline Mechanical polishing & Mechanical friction and material removal & Low efficiency & $\begin{array}{l}\text { The final surface accuracy of } 1 \mathrm{~nm} \\
\text { RMS was reported by Paquin et al. [3] }\end{array}$ \\
\hline Wet polishing & $\begin{array}{l}\text { Polished mold is immersed in the slurry, } \\
\text { RMS becomes lower by an abrasive }\end{array}$ & High surface accuracy & $\begin{array}{l}\text { The final surface accuracy of } 0.75 \mathrm{~nm} \\
\text { RMS was reported by Xu et al. [4] }\end{array}$ \\
\hline Ultraprecision grinding & Ductility grinding & Equipment require high & $\begin{array}{l}\text { Bifano et al. [5] has used CVD SiC to } \\
\text { obtain the } 5.5 \mathrm{~nm} \text { RMS }\end{array}$ \\
\hline Tribochemical polishing & The tribochemical reaction & Low efficiency & $\begin{array}{l}\text { In [6], final surface accuracy of } 1 \mathrm{~nm} \\
\text { RMS }\end{array}$ \\
\hline $\begin{array}{l}\text { Electrolytic in-process } \\
\text { dressing (ELID) }\end{array}$ & $\begin{array}{l}\text { The electrolysis process so that the grinding } \\
\text { wheel functions }\end{array}$ & Good surface quality & $\begin{array}{l}\text { In [7], final surface accuracy of } 1.4 \mathrm{~nm} \\
\text { RMS }\end{array}$ \\
\hline $\begin{array}{l}\text { Chemical mechanical } \\
\text { Polishing (CMP) }\end{array}$ & $\begin{array}{l}\text { Combination of mechanical grinding and } \\
\text { chemical etching }\end{array}$ & $\begin{array}{l}\text { Good surface quality, } \\
\text { but is corrosive }\end{array}$ & $\begin{array}{l}\text { In [8], final surface accuracy of } 0.5 \mathrm{~nm} \\
\text { RMS }\end{array}$ \\
\hline $\begin{array}{l}\text { Magneto rheological } \\
\text { Finishing (MRF) }\end{array}$ & $\begin{array}{l}\text { Magnetorheological polishing fluid viscosity } \\
\text { increases the shear force generated for } \\
\text { material removal in the magnetic field } \\
\text { gradient }\end{array}$ & Low efficiency & $\begin{array}{l}\text { Johnson et al. have used this method } \\
\text { to fabricate CVD SiC [9] }\end{array}$ \\
\hline $\begin{array}{l}\text { Laser-induced } \\
\text { photochemical polishing }\end{array}$ & Laser-induced photochemical reactions & $\begin{array}{l}\text { High efficiency, but is } \\
\text { corrosive }\end{array}$ & $\begin{array}{l}\text { The final surface accuracy of } 80 \mathrm{~nm} \\
\text { RMS was reported by Murahara [10] }\end{array}$ \\
\hline Ion beam milling & $\begin{array}{l}\text { High-speed ion beam hits the surface of the } \\
\text { sample }\end{array}$ & $\begin{array}{l}\text { Good surface quality, } \\
\text { expensive equipment }\end{array}$ & $\begin{array}{l}\text { The final surface accuracy of } 1 \mathrm{~nm} \\
\text { RMS was reported by Johnson et al. } \\
{[11]}\end{array}$ \\
\hline Float polishing & $\begin{array}{l}\text { The sample is floating on the polishing plate } \\
\text { by the high-speed rotating fluid dynamic } \\
\text { pressure }\end{array}$ & Good surface quality & $\begin{array}{l}\text { In [12], final surface accuracy of } 3 \mathrm{~nm} \\
\text { RMS }\end{array}$ \\
\hline
\end{tabular}


TABle 3: Different methods for preparing CVD SiC.

\begin{tabular}{lll}
\hline Methods & Advantages and disadvantages & Example \\
\hline APCVD & $\begin{array}{l}\text { The process is simple and has fast response, but } \\
\text { with poor uniformity }\end{array}$ & $\begin{array}{l}\text { single-crystalline 3C-SiC (cubic silicon } \\
\text { carbide) thin films. The 3C-SiC film had a very } \\
\text { good crystal quality without twins, defects, or } \\
\text { dislocations, and a very low residual stress }\end{array}$ \\
\hline & $\begin{array}{l}\text { Clavaguera-Mora et al. [14] have used Si } \\
\left(\mathrm{CH}_{3}\right)_{4} \text { as the source materials to deposit SiC } \\
\text { film by hot CVD device. Films grown at }\end{array}$ \\
$\begin{array}{ll}\text { It is possible to grow thin films with uniform } \\
\text { and smooth morphology during the 3C-SiC } \\
\text { film growth. LPCVD has disadvantages of low } \\
\text { growth rate amorphous with nanocrystals } \\
\text { of mean grain size 10 nm and have smooth } \\
\text { surfaces. Surface profilometry measurements } \\
\text { give a root mean square roughness (RMS) of } \\
6 \text { nm }\end{array}$ & $\begin{array}{l}\text { Novi et al. [15] have used PECVD to prepare } \\
\text { amorphous SiC, and there has been a lot of } \\
\text { cubic structures on the surface, which indicates } \\
\text { the existence of polycrystalline structures }\end{array}$ \\
\hline
\end{tabular}

and it is one of the most effective methods for surface modification to prepare $\mathrm{SiC}$-based reflection mirror. But the CVD process with high substrate temperature $\left(>1000^{\circ} \mathrm{C}\right)$ would lead to the deformation of SiC-matrix. Another disadvantage of the CVD process is time consumption.

There are different treating methods for CVD SiC process, including atmospheric pressure chemical vapor deposition $\mathrm{SiC}$ (APCVD SiC), low-pressure chemical vapor deposition $\mathrm{SiC}$ (LPCVD SiC), and plasma enhanced chemical vapor deposition SiC (PECVD SiC) [32-34]. Different methods for preparing CVD $\mathrm{SiC}$ are shown in Table 3.

CVD SiC coating has been widely applied to surface modification of $\mathrm{SiC}$ matrix. For example, CVD $\mathrm{SiC}$ with $0.2 \mathrm{~nm}$ RMS on the $\mathrm{C} / \mathrm{SiC}$ substrates had been reported by Trex Advanced Materials [21]. The CVD SiC on S-SiC substrates in the polished roughness of less than $0.1 \mathrm{~nm}$ has also been reported by BOOSTEC. In China, Zhang [35] applied this method to obtain CVD-SiC with the surface roughness of $1.478 \mathrm{~nm}$ RMS.

3.3.2. PVD SiC. High temperature (typically $1300^{\circ} \mathrm{C}$ ) in the preparation process of CVD $\mathrm{SiC}$ may result in stronger film stress on the SiC mirror. This is due to the unacceptable high residual stress buildup in heavy cross-sections. The cost of producing CVD $\mathrm{SiC}$ as a large self-supporting substrate is very high. However, PVD $\mathrm{SiC}$ appears to be very attractive due to its relative simplicity, low substrate temperature, and wide accessibility by industry.

Ion-Assisted Deposition SiC (IAD SiC). The ion implantation of semiconductors rapidly became an accessible technology from the 1970s because of its ability to produce superior electronic devices. Ion beam modification of nonsemiconductor materials for enhancing surface sensitive properties has been actively pursued in the international R\&D community. The advantages of this technique include high density, superior adhesion, and the ability to produce arbitrarily thick coatings. Perhaps the most important feature of the IBAD technology is the frequently demonstrated ability to control many coatings properties such as morphology, adhesion, and stress, as well as stoichiometry. The amorphous $\mathrm{SiC}$ coating with large area can be prepared by this method on the SiC substrate. The $\alpha$-SiC coating has been prepared on the $\mathrm{RB} \mathrm{SiC}$ and polished with surface roughness up to $0.2 \mathrm{~nm}$ RMS by U.S. HDOS [3, 36] using ion beam deposition method. Hall ion source [37] and high-energy Kaufman ion source [38] can both be used as the ion-beam resources for preparing $\alpha$-SiC and its system of SiC-modified membrane and the surface roughness can be down to $0.867 \mathrm{~nm}$ RMS and $0.743 \mathrm{~nm}$ RMS.

Magnetron Sputtering SiC Clapping. Magnetron sputtering is used widely due to its low cost, high deposition rate, low deposition temperature, and good adhesion of the film feature. The $\mathrm{SiC}$ coatings were deposited by RF magnetron sputtering from a sintered $\mathrm{SiC}$ target onto commercially monopolished RB SiC substrate kept at low temperature. The deposition rate is fast and the desired temperature is low, but the film stability of its system is not sustainable [39]. Magnetron sputtering SiC clapping was prepared with the roughness down to $1.394 \mathrm{~nm}$ RMS [40] and $3.184 \mathrm{~nm} \mathrm{RMS}$ as shown in Figure 2 by Tang et al. [22] and the surface roughness of 2 angstrom by Kortright and Windt [41].

Pulsed Laser Deposition SiC (PLD SiC). PLD is a relatively new technique and attracting great attention for its simplicity, reduced investment cost, and flexibility. In the PLD process [42], a high flux pulsed laser beam is focused on the target material leading to the formation of a plasma plume. The high heating rate of the target surface $(\approx 100 \mathrm{~K} / \mathrm{s})$ due to pulsed laser irradiation leads to a congruent evaporation of the target irrespective of the evaporating point of its constituent elements or compounds, so that the target stoichiometry can be retained in the deposited films. 

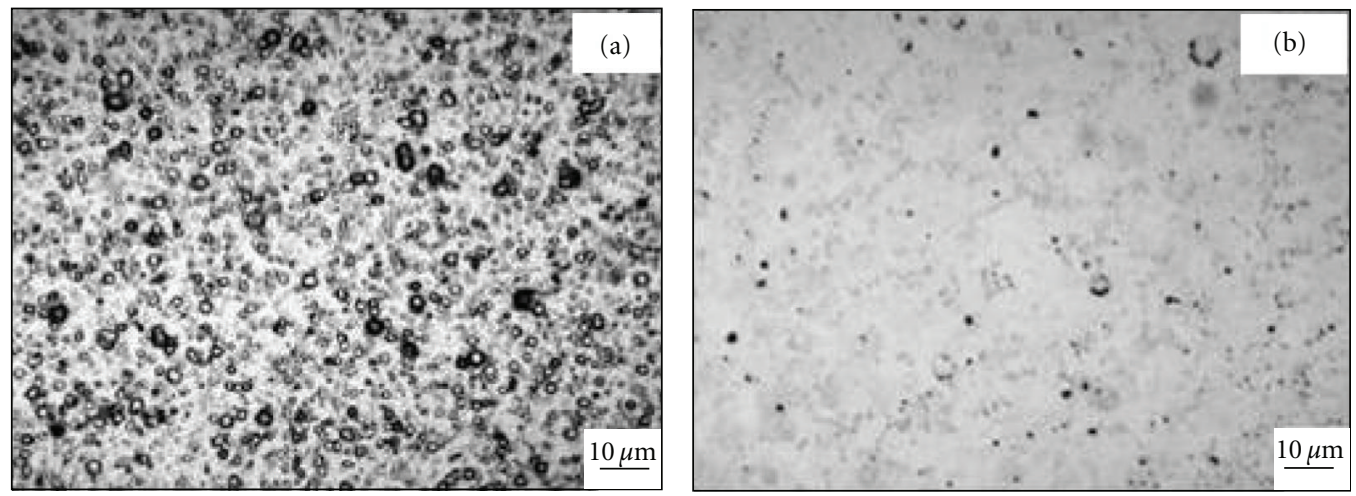

Figure 2: Photomicrograph of (a) unpolished, (b) polished PVD SiC coating on RB SiC, reprinted with permission from [22].

TABLE 4: Thermal performance of RB-SiC and Si [16].

\begin{tabular}{lccccc}
\hline Materials & $\alpha /(\mathrm{ppm} / \mathrm{K})$ & $K /(\mathrm{W} / \mathrm{mK})$ & $D$ & $\alpha / K$ & $\alpha / D$ \\
\hline RB-SiC & 2.4 & 170 & 80 & 0.014 & 0.03 \\
$\mathrm{Si}$ & 2.6 & 156 & 89 & 0.017 & 0.029 \\
\hline
\end{tabular}

Furthermore, because of the high heating rate of the ablated materials, PLD of crystalline films demands a much lower substrate temperature than other film growing techniques. The major drawback of this technique is that the high energy involved in the process also leads to the formation of microparticulate on the thin film surface. Vendan et al. [43] has prepared $\alpha$-SiC thin films by fs-PLD and ns-PLD techniques and found that the surface roughness of $\mathrm{SiC}$ films by the ns-PLD technique was bigger than that by fs-PLD. Magida et al. [32] has prepared $\mathrm{SiC}$ thin films which exhibit high reflectivity in the ultraviolet band $(40.7 \mathrm{~nm}-121.6 \mathrm{~nm})$ and the surface roughness of $1 \mathrm{~nm}$ RMS.

Ion Beam Sputtering SiC (IBS SiC). The ion beam engine concept was firstly developed in the United States. By the IBS technique, the $\mathrm{SiC}$ films being flat and smooth, a large area of dense internal stress and low defect density can be obtained. For example, the IBS SiC coatings have been prepared and polished to be less than 2 A RMS by Johnson [36] for the optical system requiring ultralow scatter performance.

3.4. Si Clapping. The thermal properties of Si coating match well with that of SiC as shown in Table 4, then Si clapping can be used for the surface modification of SiC. It can be seen that their thermal performance is well matched, and Si can be used as a good reflector material. CVD and PVD are the main preparation methods.

3.4.1. CVD Si Clapping. The Si clapping is easier to be polished well with better surface quality and low-cost SiCclapping. Polycrystalline Si produced by a scalable CVD process has exhibited a surface finish of $0.2 \mathrm{~nm}$ RMS. Polycrystalline Si was fabricated by reacting trichlorosilane $\left(\mathrm{SiHCl}_{3}\right)$ with excess $\mathrm{H}_{2}$ in a hot-wall CVD reactor according to the reaction: $\mathrm{SiHCl}_{3}+2 \mathrm{H}_{2} \rightarrow \mathrm{Si}(\mathrm{s})+4 \mathrm{HCl}(\mathrm{g})$. However, it is not widely applied $[14,44]$ because columnar structure is often present in CVD Si.

Polycrystalline Si [19] was also used to clad on several advanced ceramic materials such as $\mathrm{SiC}$, sapphire, pyrolytic $\mathrm{BN}$, and $\mathrm{Si}$ by a chemical vapor deposition (CVD) process. The thickness of Si cladding ranged from 0.025 to $3.0 \mathrm{~mm}$. CVD Si adhered quite well to all the above materials, where the Si cladding was highly stressed and cracked. The surface roughness can reach $0.2 \mathrm{~nm}$ RMS after polishing. Amorphous silicon thin films were formed by chemical vapor deposition by Choi et al. [45]. The amorphous silicon films without reflector bias voltage exhibit $0.119 \mathrm{~nm}$ RMS, but down to $0.171 \mathrm{~nm}$ RMS with reflector bias voltage of $-120 \mathrm{~V}$, respectively.

3.4.2. PVD Si Clapping. CVD $\mathrm{Si}$ is generally prepared with high temperature $\left(>600^{\circ} \mathrm{C}\right)$, and the PVD Si film is widely used. The application of $\mathrm{Si}$ coating can reduce surface wearing resistance of $\mathrm{SiC}$ ceramic without changing mechanical properties of the bulk materials. The efficiency of surface finishing for large optical components can be greatly improved as well [23]. Therefore, PVD Si appears to be very attractive because of its relative simplicity, low substrate temperature, and wide accessibility by industry. Si clapping is easier to be polished well because it is single-phase material without the different heterogeneous phase in the polishing process. PVD Si coating is now becoming a preferred method of the SiC surface modification.

Vacuum Evaporation Si Clapping. Vacuum evaporation deposition of Si film is processed in a high vacuum by heating the Si gasification or sublimation condensing into Si film and thus being deposited on SiC substrate surface. The method is relatively simple and has high deposition rate. But the columnar structure is present in Si film and the physical property of Si film is not stabile. Zhao [46] has obtained amorphous Si films by thermal evaporation. In recent years, this method has been improved. Fang et al. [47] deposited Si film on steel and alumina substrates by electron beam evaporation of solid silicon. 

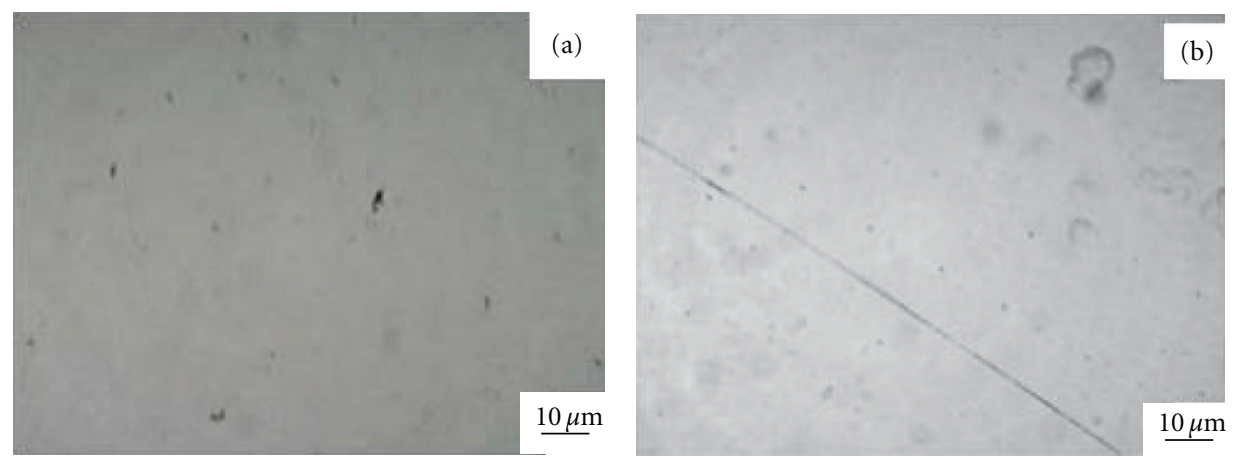

FIGURE 3: Photomicrograph of (a) unpolished, (b) polished PVD Si coating on RB SiC, reprinted with permission from [22].

Magnetron Sputtering Si Clapping. Magnetron sputtering (belongs to PVD) appears to be very attractive due to its relative simplicity and low substrate temperature. Many researchers have studied this method, Aoucher et al. [48] deposited amorphous silicon by DC magnetron sputtering on a quartz substrate at a rate around $1.5 \mathrm{~nm} / \mathrm{s}$. Tang et al. [22] has used RF magnetron sputtering method to prepare Si film with the surface roughness from $17.992 \mathrm{~nm}$ RMS to $1.183 \mathrm{~nm}$ RMS as shown in Figure 3.

Ion-Beam-Assisted Si Clapping. Hydrogenated amorphous silicon (a-Si:H) films are generally prepared by glowdischarge decomposition of silane or by sputtering of silicon in an argon-hydrogen mixture. The reaction temperature is low $\left(200^{\circ} \mathrm{C}\right)$ and the preparation parameters can be controlled. So it was used to prepare amorphous silicon films.

Photoconductive hydrogenated amorphous silicon films were deposited by ion-beam-assisted evaporation using hydrogen-argon plasma. Surface modification for the RB-SiC substrate [49] is carried out using e-beam evaporation with plasma ion assisted. The surface roughness of the RB-SiC substrate is reduced to $0.0632 \mathrm{~nm}$, the scattering coefficient is reduced to $2.81 \%$, and the average reflectance from $500 \mathrm{~nm}$ to $1000 \mathrm{~nm}$ is raised to $97.05 \%$; these data indicate that good optical quality similar to that of the fine polished glass ceramics can be obtained by the modification process.

Plasma-Ion-Assisted of Deposition Si Clapping. For the production of thin films of high quality standard, thermal evaporation techniques are applied with the assistance of ion sources which provide additional energy and momentum to influence the growth process. Larger ion current densities on increased substrate areas can be generated by employing plasma sources, and the process is plasma-ion-assisted deposition (PIAD) [50]. In PIAD, a growing thin film is bombarded by energetic ions from a plasma ion source and the columnar microstructure of the film is disrupted, resulting in the improved optical and mechanical properties of thin films [51]. Liu et al. [23] has prepared Si thin film by this method and obtained continuous, homogenous, wellbonded amorphous $\mathrm{Si}$ coatings on $\mathrm{SiC}$ ceramics. It means that the SiC substrate can be fully covered up and the effect of substrate surface defects on the surface morphology of the Si coating can be overlooked as shown in Figure 4.

Recently, the PVD Si coatings on SiC substrates have been investigated. SSG has applied PVD Si in optical systems of the GEO telescope [52], designed and constructed for an SBIR program funded by NASA's Marshall Space Flight Center (MSFC). The SiC telescope and "GOES-like" scan mirror are designed to "generic" GEO specifications, and the surface roughness decreased to $0.4 \mathrm{~nm}$ RMS after polishing. In China, the PVD Si coatings deposited on the surface of polished $\mathrm{RB}-\mathrm{SiC}$ and $\mathrm{S}-\mathrm{SiC}$ were demonstrated to improve the optical surface quality after being polished by Tang et al. [22]. Both the surfaces of PVD Si coating on RB-SiC and $\mathrm{S}-\mathrm{SiC}$ are smoother than that of bare $\mathrm{SiC}$. The RMS can reach to the angstrom grade, and the reflectance improves significantly.

\section{Conclusion}

Silicon carbide as the third generation of space mirror material has attracted more and more attention and is widely applied. Silicon carbides prepared by different preparation methods have their advantages, but still cannot meet the optical requirements ( $<1 \mathrm{~nm}$ RMS) after the current optical processing. The surface roughness and reflection rate of the $\mathrm{SiC}$ material can be well improved after surface modification. Especially in the CVD SiC coating and PVD-Si coating on the $\mathrm{SiC}$ ceramic, surface roughness of Angstrom level can be reached. All kinds of surface-modification methods have been developed and every method has its disadvantages. The hot press glass has some drawbacks for usage of the glass cladding on large surfaces. The $\mathrm{C} / \mathrm{SiC}$ coating may not be suitable for low surface roughness $(<1 \mathrm{~nm}$ RMS). The CVD process with high temperature $\left(>1000^{\circ} \mathrm{C}\right)$ would lead to the deformation of SiC matrix. PVD method to prepare SiC-film is slower and the modified film is very difficult to be polished. In our view, PIAD Si has low reaction temperature $\left(<300^{\circ} \mathrm{C}\right)$ and is very easy to be polished. The preparation process is relatively simple, and reproducible preparation of siliconmodified layer gives a dense structure, combined with the base firmly. Therefore, PVD Si is the best choice for surface modification of $\mathrm{SiC}$ mirror because of its relative simplicity, low substrate temperature, and wide accessibility by industry, especial PIAD Si. 


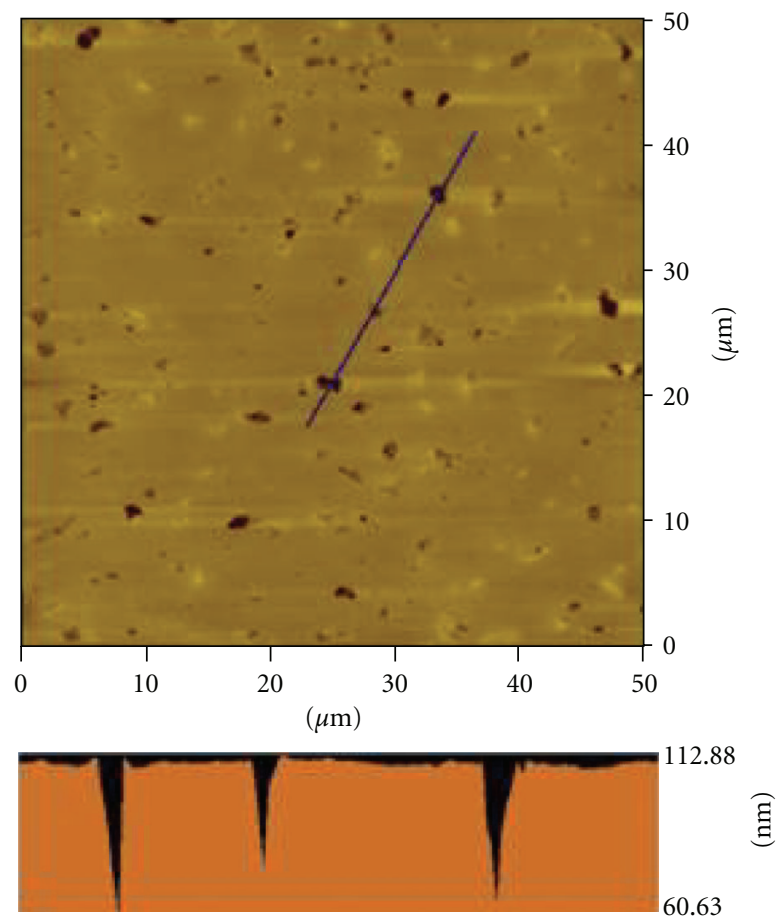

FIGURE 4: Surface topography of Si coating tested by AFM, reprinted with permission from [23].

\section{Acknowledgments}

Y. Yang thanks the Century Program (One-Hundred-Talent Program) of the Chinese Academy of Sciences for special funding support. This study was also supported in part by a fund from the National Natural Science Foundation of China (no. 51071167, 51102266), the Shanghai Yangtze River Delta Science Project (no. 11495810100), and the Shanghai Pujiang Program (10PJ1410700).

\section{References}

[1] J. Robichaud, J. J. Guregian, and M. Schwalm, "SiC optics for Earth observing applications," in Earth Observing Systems VIII, vol. 5151 of Proceedings of SPIE, pp. 53-62, August 2003.

[2] S. G. Johnson, "SiC coatings on $\mathrm{RB}$ SiC mirrors for ultrasmooth surfaces," vol. 2018 of Proceedings of SPIE, no. 1993, pp. 237-247.

[3] R. A. Paquin, M. B. Magida, and C. L. Vernold, "Large optics from silicon carbide," in Large Optics II, vol. 1618 of Proceedings of SPIE, pp. 53-60, October 1991.

[4] Q. L. Xu, F. Wu, and S. B. Wu, "Super smooth surfacing fabrication for lightweight silicon carbide plan mirror," OptoElectronic Engineering, vol. 31, pp. 22-25, 2004.

[5] T. Bifano, Y. Yi, and K. Kahl, "Fixed abrasive grinding of CVD SiC mirrors," Precision Engineering, vol. 16, no. 2, pp. 109-116, 1994.

[6] Z. Z. Zhu, V. Muratov, and T. E. Fischer, "Tribochemical polishing of silicon carbide in oxidant solution," in Proceedings of the 12th International Conference on Wear of Materials, vol. 225-229, pp. 848-856, Atlanta, Ga, USA, 1999.

[7] W. Lin, H. Ohmori, T. Suzuki, Y. Uehara, and S. Morita, "Polishing characteristics of ELID-ground surface of nano precision optical elements," Key Engineering Materials, vol. 291-292, pp. 365-370, 2005.

[8] L. Zhou, V. Audurier, P. Pirouz, and J. A. Powell, "Chemomechanical polishing of silicon carbide," Journal of the Electrochemical Society, vol. 144, no. 6, pp. L161-L163, 1997.

[9] J. S. Johnson, K. Grobsky, and D. J. Bray, "Rapid fabrication of lightweight silicon carbide mirrors," in Optomechanical Design and Engineering, vol. 4771 of Proceedings of SPIE, pp. 243-253, July 2002.

[10] M. Murahara, "Excimer laser-induced photochemical polishing of $\mathrm{SiC}$ mirror," in Laser-Induced Damage in Optical Materials, vol. 4679 of Proceedings of SPIE, pp. 69-74, October 2001.

[11] J. S. Johnson, K. Grobsky, and D. J. Bray, "Rapid fabrication of lightweight silicon carbide mirrors," in Optomechanical Design and Engineering, Proceedings of SPIE, pp. 243-253, July 2002.

[12] D. Fan, Z. Y. Zhang, and H. Y. Niu, "Surfacing fabrication of silicon carbide optical mirror," Journal of Inorganic Materials, vol. 31, pp. 1096-1100, 2003.

[13] G. S. Chung and K. S. Kim, "Heteroepitaxial growth of single 3C-SiC thin films on $\mathrm{Si}(100)$ substrates using a single-source precursor of hexamethyldisilane by APCVD," Bulletin of the Korean Chemical Society, vol. 28, no. 4, pp. 533-537, 2007.

[14] M. T. Clavaguera-Mora, J. Rodríguez-Viejo, Z. El Felk et al., "Growth of SiC films obtained by LPCVD," Diamond and Related Materials, vol. 6, no. 10, pp. 1306-1310, 1997.

[15] A. Novi, G. Taglioni, and L. Novella, "Silicon carbide for mirrors by plasma enhanced chemical vapour deposition at low temperature," European Space Agency ESA SP, vol. 554, pp. 687-691, 2004.

[16] L. D. Xu, X. J. Zhang, and X. Wang, "Surface coating technique of reaction bonded sic mirrors," Opto-Electronic Engineering, vol. 36, no. 1, pp. 120-124, 2009. 
[17] C. J. Shih and A. Ezis, "Application of hot-pressed silicon carbide to large high-precision optical structures," in Silicon Carbide Materials for Optics and Precision Structures, vol. 2543 of Proceedings of SPIE, pp. 24-37, July 1995.

[18] G. Liu, Z. Huang, X. Liu, and D. Jiang, "Removal behaviors of different SiC ceramics during polishing," Journal of Materials Science and Technology, vol. 26, no. 2, pp. 125-130, 2010.

[19] J. S. Goela and R. L. Taylor, "Chemical vapor deposition for silicon cladding on advanced ceramics," Journal of the American Ceramic Society, vol. 72, pp. 1747-1750, 1989.

[20] Y. Y. Han, Y. M. Zhang, and J. C. Han, "Current status of research on silicon carbide mirror technology," Materials Review, vol. 19, pp. 5-8, 2005.

[21] H. Zhou, C. R. Zhang, and Y. B. Cao, "Lightweight C/SiC mirrors for space application," Large Mirrors and Telescopes, vol. 6148, pp. L1480-L1486, 2006.

[22] H. Tang, Z. Huang, and S. Tan, "PVD SiC and PVD Si coatings on RB SIC for surface modification," in Proceedings of the 2 nd International Symposium on Advanced Optical Manufacturing and Testing Technologies-Advanced Optical Manufacturing and Testing Technologies, pp. 1-6, November 2005.

[23] G. L. Liu, Z. R. Huang, J. H. Wu, and X. J. Liu, "Surface morphology evolution and properties of silicon coating on silicon carbide ceramics by advanced plasma source ion plating," Surface and Coatings Technology, vol. 207, pp. 204210, 2012.

[24] J. Yan, Z. Zhang, and T. Kuriyagawa, "Mechanism for material removal in diamond turning of reaction-bonded silicon carbide," International Journal of Machine Tools and Manufacture, vol. 49, no. 5, pp. 366-374, 2009.

[25] H. Y. Tam, H. B. Cheng, and Y. W. Wang, "Removal rate and surface roughness in the lapping and polishing of RBSiC optical components," Journal of Materials Processing Technology, vol. 192-193, pp. 276-280, 2007.

[26] G. L. Liu, Z. R. Huang, and X. J. Liu, "Recent developments of surface coatings and optical fabrication of silicon carbide," Journal of Inorganic Materials, vol. 22, pp. 769-774, 2007.

[27] A. Venu Gopal and P. V. Rao, "The optimisation of the grinding of silicon carbide with diamond wheels using genetic algorithms," International Journal of Advanced Manufacturing Technology, vol. 22, no. 7-8, pp. 475-480, 2003.

[28] H. B. Cheng, Z. J. Feng, and Y. W. Wang, "Magnetorheological finishing of SiC aspheric mirrors," Materials and Manufacturing Processes, vol. 20, pp. 917-931, 2005.

[29] M. Deyerler, N. Pailer, R. Wagner, and C. Mueller, "Ultralightweight mirrors: recent developments of C/SiC," in Optical Design, Materials, Fabrication, and Maintenance, vol. 4003 of Proceedings of SPIE, pp. 73-79, March 2000.

[30] A. Novi, G. Mondello, C. Devilliers et al., "Comparison of sintered-SiC and $\mathrm{C} / \mathrm{SiC}$ mirrors behaviour at cryotemperatures," in Optical Materials and Structures Technologies, vol. 5179 of Proceedings of SPIE, pp. 246-253, August 2003.

[31] B. Harnisch, B. Kunkel, M. Deyerler, and S. Bauereisen, "Ultralightweight C/SiC Mirrors and Structures," ESA BulletinEuropean Space Agency, vol. 95, pp. 108-112, 1998.

[32] M. B. Magida, R. A. Paquin, and J. J. Richmond, "Dimensional stability of bare and coated reaction bonded silicon carbide," in Dimensional Stability, vol. 1335 of Proceedings of SPIE, pp. 60-68, July 1990.

[33] C. Hung Wu, C. A. Zorman, and M. Mehregany, "Growth of polycrystalline $\mathrm{SiC}$ films on $\mathrm{SiO}_{2}$ and $\mathrm{Si}_{3} \mathrm{~N}_{4}$ by APCVD," Thin Solid Films, vol. 355-356, pp. 179-183, 1999.
[34] R. J. Liu, C. R. Zhang, X. G. Zhou, and Y. B. Cao, "SiC coatings for mirrors prepared by low pressure chemical vapor deposition," Journal of Materials Science Letters, vol. 22, no. 11, pp. 841-843, 2003.

[35] J. H. Zhang, Y. M. Zhang, J. C. Han, X. D. He, and W. Yao, "Design, fabrication and testing of space-borne SiC mirror," Optics and Precision Engineering, vol. 14, no. 2, pp. 179-184, 2006.

[36] S. Johnson, "SiC coating on $\mathrm{RB} \mathrm{SiC}$ mirror for ultra-smooth surface," vol. 2018 of Proceedings of SPIE, pp. 237-247, 1993.

[37] T. T. Wang, J. S. Gao, X. Y. Wang et al., "Preliminary study of reaction bonded silicon carbide surface modification," Optics and Precision Engineering, vol. 16, no. 9, pp. 1603-1607, 2008.

[38] J. S. Gao, T. T. Wang, Q. Song et al., "Preparation of silicon carbide surface-modified coatings with end hall ion source assisted," Infrared and Laser Engineering, vol. 37, no. 4, pp. 710-713, 2008.

[39] G. Monaco, M. Gastaldi, and P. Nicolosi, "Silicon carbide thin films for EUV and soft X-ray applications,” European Physical Journal, vol. 169, pp. 159-165, 2009.

[40] H. Tang, S. Tan, Z. Huang, S. Dong, and D. Jiang, "Surface morphology of $\alpha$-SIC coatings deposited by RF magnetron sputtering," Surface and Coatings Technology, vol. 197, no. 23, pp. 161-167, 2005.

[41] J. B. Kortright and D. L. Windt, "Amorphous silicon carbide coatings for extreme ultraviolet optics," Applied Optical, vol. 27, no. 14, pp. 2841-2846, 1988.

[42] I. Hanyecz, J. Budai, E. Szilágyi, and Z. Tóth, "Characterization of pulsed laser deposited hydrogenated amorphous silicon films by spectroscopic ellipsometry," Thin Solid Films, vol. 519, no. 9, pp. 2855-2858, 2011.

[43] M. Vendan, P. Molian, A. Bastawros, and J. Anderegg, "Ultrashort pulsed laser deposition and patterning of SiC thin films for MEMS fabrication," Materials Science in Semiconductor Processing, vol. 8, no. 6, pp. 630-645, 2005.

[44] Y. F. Zhou, Y. M. Zhang, and J. C. Han, "Preparation of silicon coating," Materials Review, vol. 19, pp. 84-86, 2005.

[45] S. G. Choi, S. J. Wang, H. H. Park et al., "Properties of amorphous silicon thin films synthesized by reactive particle beam assisted chemical vapor deposition," Thin Solid Films, vol. 518, no. 24, pp. 7372-7376, 2010.

[46] X. J. Zhao, "Investigation of silicon carbide mirror's reflective performance and film design," Harbin Harbin Institute of Technology, 2007.

[47] P. H. Fang, P. Bai, J. H. Kinnier, Z. Huan, and C. C. Schubert, "Temperature dependent formation of microcrystal and amorphous silicon by vacuum evaporation," Journal of Non-Crystalline Solids, vol. 59-60, no. 2, pp. 819-821, 1983.

[48] M. Aoucher, G. Farhi, and T. Mohammed-Brahim, "Crystallization of hydrogenated amorphous silicon deposited at high rate by dc magnetron sputtering," Journal of Non-Crystalline Solids, vol. 227-230, no. 2, pp. 958-961, 1998.

[49] Z. F. Shen, J. S. Gao, H. Chen, X. Y. Wang, T. T. Wang, and X. M. Zheng, "Performance and reliability evaluation for the surface modification of space used silicon carbide mirror," Acta Photonica Sinica, vol. 38, no. 9, pp. 2353-2358, 2009.

[50] J. Harhausen, I. Meyenburg, A. Ohl, and R. Foest, "Characterization of the plasma plume of a PIAD plasma source by means of optical emission spectroscopy," Surface and Coatings Technology, vol. 205, no. 2, pp. S407-S410, 2011.

[51] S. H. Woo and C. K. Hwangbo, "Influence of plasma ion-beam assistance on $\mathrm{TiO}_{2}$ and $\mathrm{MgF}_{2}$ thin films deposited by plasma 
ion-assisted deposition," Surface and Coatings Technology, vol. 201, no. 19-20, pp. 8250-8257, 2007.

[52] M. I. Anapol, L. R. Gardner, T. W. Tucker, and R. J. Koczor, "Lightweight 0.5-m silicon carbide telescope for a geostationary earth observatory mission," in Silicon Carbide Materials for Optics and Precision Structures, Proceedings of SPIE, pp. 164172, July 1995. 

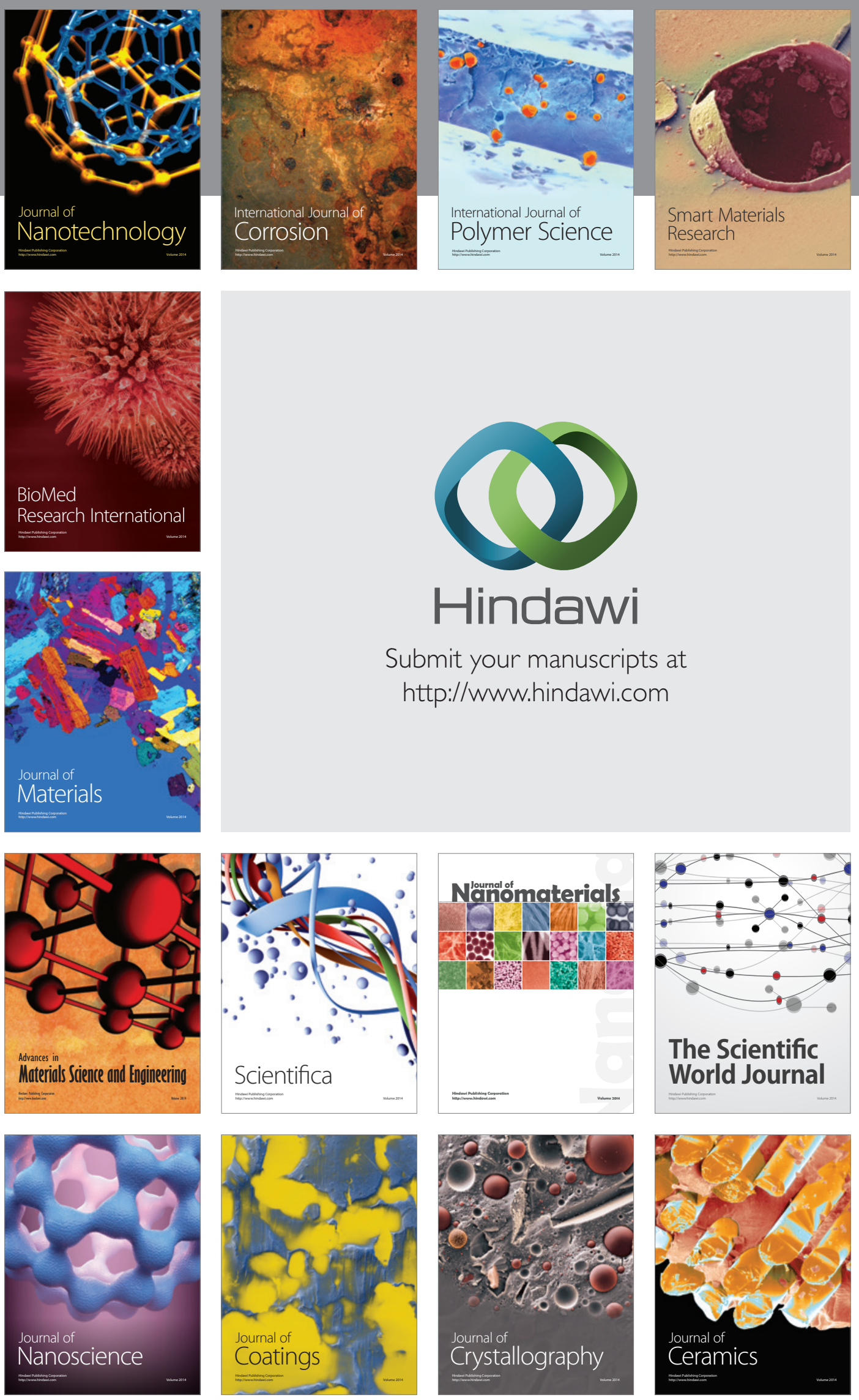

The Scientific World Journal

Submit your manuscripts at

http://www.hindawi.com

\section{World Journal}

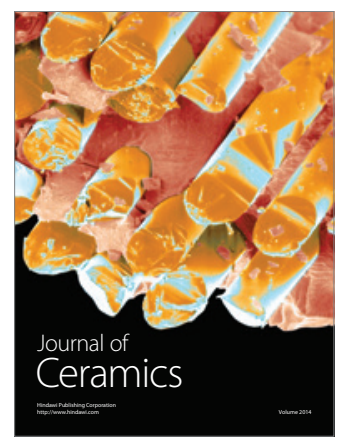

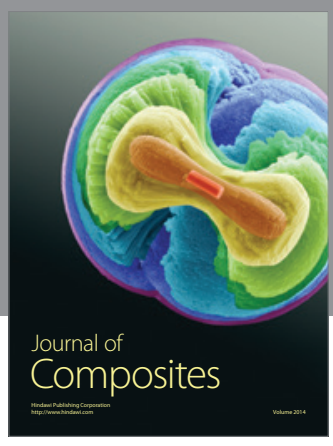
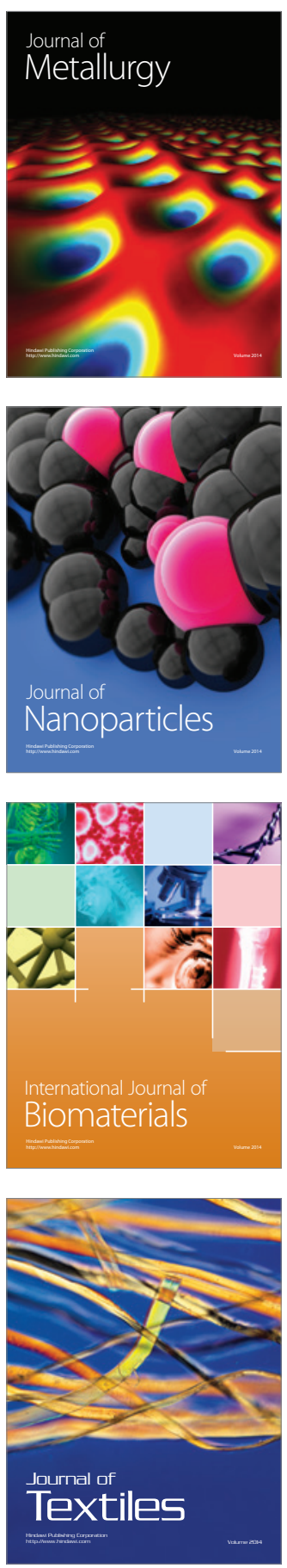